American Journal of Applied Sciences 6 (5): 806-810, 2009

ISSN 1546-9239

(C) 2009 Science Publications

\title{
Bacterial Contamination and Resistance to Commonly Used Antimicrobials of Healthcare Workers' Mobile Phones in Teaching Hospitals, Kerman, Iran
}

\author{
Gholamreza Sepehri, Nooshin Talebizadeh, Ali Mirzazadeh, \\ Touraj- Reza Mir-shekari and Ehsan Sepehri \\ Physiology Research Center, Neuroscience Research Center, \\ University of Medical Sciences, Kerman, Iran
}

\begin{abstract}
Problem Statement: The contamination rates of Health Care Worker's (HCW) mobile phones and resistance to commonly used antimicrobials were evaluated in three teaching hospitals in Kerman, Iran. So, we examined 150 randomly selected HCWs in three teaching hospitals in Kerman, Iran, 2007. For each HCW a sterile swab moistened with sterile water was rotated over the surface of both sides of his/her phone, a second swab for the sampling of the dominant hand. Both swabs were cultured by the routine methodology in use at laboratory. Plates were incubated aerobically at $37^{\circ} \mathrm{C}$ for $48 \mathrm{~h}$. Approach: All samples were examined for the antimicrobial activity for commonly used antimicrobials using disc diffusion method. Results: A total of 48 (32.0\%, CI95 24.6-40.1\%) mobile phones and $59(39.3 \%$, CI95 31.5-47.6\%) of dominant hands had bacterial contamination and Staphylococcus epidermidis was the most commonly cultured organisms from all sites. The resistance rates to commonly used antimicrobials in isolated bacteria from phones and dominant hand varied from $6.7 \%$ for cephalothin to $25 \%$ for amoxicillin, respectively. Conclusions/Recommendations: The kind of isolated microorganisms and their susceptibility to commonly used antimicrobials from dominant hands were almost similar with those from phones $(p<0.05)$. In conclusion, the results indicated that the rate of bacterial contamination of the HCW's phone is just below $50 \%$, accompanying with a resistance rate to the common used antibiotics in one fourth of all the cases. Therefore, mobile phones could be an important source of nosocomial infections and the spread of bacterial resistance bacteria in medical healthcare settings.
\end{abstract}

Key words: Healthcare workers, mobile phones, nosocomial Infections, antimicrobial resistance

\section{INTRODUCTION}

Nosocomial infections caused by multi-drugresistant gram-positive organisms such as Staphylococcus aureus and enterococcal species are a growing problem in many health care institutions ${ }^{[1-3]}$. Hands and instruments used by healthcare workers (HCWs) may serve as vectors for the nosocomial transmission of microorganisms ${ }^{[4,5]}$. The use of mobile phones by medical personnel may serve as potential vehicles for the spread of nosocomial pathogens and the associated nosocomial transmission of pathogens ${ }^{[1,3,6-8]}$.

A well-practiced infection control plan that encompasses hand hygiene, environmental decontamination, surveillance and contact isolation is effective for prevention of such nosocomial infections ${ }^{[3,9,10]}$. Despite these measures, colonization of potentially pathogenic organisms on various objects, such as stethoscopes, bronchoscopes, pagers, ballpoint pens, patient hospital charts, computer keyboards and mobile phones has been reported as a potential vehicle for transmission of nosocomial pathogens from $\mathrm{HCWs}^{[1,7,8,11-13]}$.

Nowadays, the usage of mobile phone in health care services is being increased. Innovations in mobile communication have led to better patient control of diabetes and asthma, and increased uptake of vaccinations by travelers reminded by Short Message Service (SMS $)^{[14-17]}$. The increased use of mobile phones is seen against a background rise in nosocomial infection rates reported by ecological findings ${ }^{[5]}$.

Hand washing may not usually be performed often enough and many people may use personal mobile phone in the course of a working day, the potential act of mobile phones as a source of microbial transmission is considerable ${ }^{[7,18]}$. Since there is no data on the risk of contamination of personal mobile phones in HCWs in teaching hospitals in Iran, so this study was undertaken

Corresponding Author: Gholamreza Sepehri, Physiology Research Center, Neuroscience Research Center, University of Medical Sciences, Kerman, Iran 
to investigate the potential role of personal mobile phone in the transmission of nosocomial pathogens and resistance to commonly used antimicrobials in HCWs including doctors, nurses and medical students in Kerman teaching hospitals, Iran.

\section{MATERIALS AND METHODS}

This cross-sectional study was conducted in 2007 in three teaching hospitals of Kerman University of medical sciences. Kerman (the center of Kerman province) is situated $1,000 \mathrm{Km}$ from Tehran in south of Iran having around 600,000 residents.

A total of $150 \mathrm{HCWs}$ (50 from each hospital) were included in the study. Microbial samples were collected from mobile phones and dominant hands of HCWs. For each $\mathrm{HCW}$, a sterile swab moistened with sterile water was rotated over the surface of both sides of his/her phone, a second swab for the sampling of the dominant hand and both swabs were immediately streaked on two plates that consist of blood agar supplemented with 5\% defibrinated sheep blood and Eosin Methylene Blue (EMB) agar. Plates were incubated aerobically at $37^{\circ} \mathrm{C}$ for $48 \mathrm{~h}$. Based on colony morphology, positive cultures were Gram stained and Gram-positive organisms were subcultured on blood agar plates (Padtan Teb Co, Iran) Gram-negative rods were subcultured on MacConkey agar (Padtan Teb Co, Iran). Organisms were identified using standard methods and API Identification System (bioMérieux, Basingstoke, $\mathrm{UK})^{[19]}$.

Gram positive and gram-negative isolates bacterial sensitivity to commonly used antimicrobials (amoxicillin, cephalothin, gentamicin) were investigated by disk diffusion method using NCCLS guidelines ${ }^{[20,21]}$ Data were entered and analyzed by Stata v. 8. Person identification code was used as primary sampling unit. All the statistics calculated by XT series of commands which handle cross-sectional time-series data. The percentage of different kind of microorganism and their antimicrobial sensitivity was reported by point estimation and confidence interval $95 \%$. The percentage of agreement on the kind of microorganism isolated from hands and phone's was tested by Kappa statistics.

\section{RESULTS}

The HCWs aged from 20-53 with the mean age of 34.17 (SD 7.58) years. About $77 \%$ of them were women. $33.6 \%$ of HCWs were general

practitioner, $36.2 \%$ nurses, $22.1 \%$ nurse aid and $8.1 \%$ were medical students.

A total of 147 subjects (out of 150) have been used their mobile phones during work time. The duration of using mobile phones was 4.1 (SD 3.02) years. Generally 48 (32.0\%, CI95 24.6-40.1\%) mobile phones had bacterial contamination. The contamination frequency varied from $25 \%$ in medical students and nurses' phones to more than $36 \%$ in physicians' and nurse aids'. Such differences in different HCWs was not statistically significant $(\mathrm{p}=0.49)$. Staphylococcus epidermidis (77.1\%, CI 95 62.7-87.9\%) was the most commonly cultured microorganism isolated from mobile phones. The percentage of other isolated microorganisms form mobile phones is shown in Table 1. Regarding isolated microorganisms from dominant hands, 59 (39.3\%, CI95 31.5-47.6\%) cases had bacterial contamination. The contamination frequency varied from $33.3 \%$ in nurses and nurse aids to near $50 \%$ in general practitioners and medical students $(\mathrm{p}=0.33)$. S.epidermidis was the most commonly cultured bacteria (79.6\%) isolated from HCW's dominant hands.

As shown in Table 2, the resistance rates to commonly used antimicrobials in isolated bacteria from phones varied from $6.7 \%$ for cephalothin to $15.6 \%$ for gentamicin. In isolated organisms from dominant hand, the resistance rate varied from $11.7 \%$ for cephalothin to $25 \%$ for amoxicillin. The percentage of agreement in the susceptibility to commonly used antimicrobials were significantly higher than the expected agreement between mobiles phone and dominant hand isolated microorganisms $(\mathrm{p}<0.02)$ (Table 2$)$.

Table 1: Types of microorganisms isolated from phones and hands of healthcare workers in teaching hospitals, Kerman, Iran

\begin{tabular}{lcc}
\hline Bacteria & $\begin{array}{l}\text { Mobile phones } \\
(\mathrm{n}=48)\end{array}$ & $\begin{array}{l}\text { Dominant hands } \\
(\mathrm{n}=59)\end{array}$ \\
\hline Staphylococcus epidermidis & $37(77.1)$ & $47(79.7)$ \\
Staphylococcus aureus & $6(12.5)$ & $4(6.8)$ \\
Bacillus subtilis & $1(2.1)$ & $2(3.4)$ \\
Klebsiella pneumonia & $1(2.1)$ & $2(3.4)$ \\
Enterococcus spp. & 0 & $1(1.7)$ \\
Yeasts & $5(10.4)$ & $3(5.1)$ \\
\hline The percentage of agreement between phone and hand isolated
\end{tabular}
microorganisms was $54.36 \%$ with Kappa $0.098(\mathrm{z}=1.51, \mathrm{p}=0.06)$

Table 2: Antimicrobial resistance to commonly used antimicrobials for dominant hands and mobile phones among healthcare workers in teaching hospitals, Kerman, Iran

\begin{tabular}{|c|c|c|c|c|}
\hline Antibiotics & $\begin{array}{l}\text { Resistant } \\
\text { N (\%) }\end{array}$ & $\begin{array}{l}\text { Sensitive } \\
N(\%)\end{array}$ & $\begin{array}{l}\text { Highly } \\
\text { Sensitive } \\
\text { N }(\%)\end{array}$ & \\
\hline \multicolumn{5}{|l|}{ Gentamicin } \\
\hline Phone & $7(15.6)$ & $31(68.8)$ & $7(15.6)$ & $\mathrm{K}=0.17$ \\
\hline Hand & $13(21.7)$ & $44(73.3)$ & $3(5.0)$ & $\mathrm{p}=0.132$ \\
\hline \multicolumn{5}{|l|}{ Cephalothin } \\
\hline Phone & $3(6.7)$ & $38(84.4)$ & $4(8.9)$ & $\mathrm{K}=0.34$ \\
\hline Hand & $7(11.7)$ & $44(73.3)$ & $9(15.0)$ & $\mathrm{p}=0.01$ \\
\hline \multicolumn{5}{|l|}{ Amoxicillin } \\
\hline Phone & $6(13.3)$ & $15(33.3)$ & $24(53.4)$ & $\mathrm{K}=0.29$ \\
\hline Hand & $15(25.0)$ & $12(20.0)$ & $33(55.0)$ & $\mathrm{P}=0.02$ \\
\hline
\end{tabular}

K: Kappa, P: p value, The percentage reported in ( ) were calculated in each row 
Am. J. Applied Sci., 6 (5): 806-810, 2009

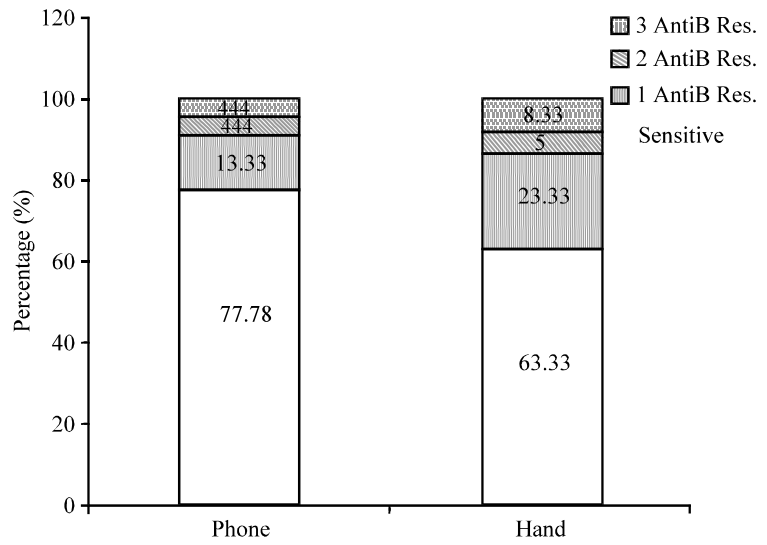

Fig. 1: The percentage of resistance to three commonly used antibiotics in isolated microorganisms from phones and dominant hands of health care workers. Antib Res: resistance to one antimicrobial agent, Antib Res: resistance to two antimicrobial agents, Antib Res: resistance to three antimicrobial agents

It was found that about $79 \%$ of bacteria isolated from phones were sensitive to all three antibiotics used in this study and $4.4 \%$ were resistant to all of these antibiotics. Also about $63.3 \%$ of isolated bacteria from hands were sensitive to all three antibiotics and 8.3\% were resistant to all of these antibiotics (Fig. 1).

Only one mobile phone grew more than one microorganism species including S.epidermidis, Klebsiella pneumonia and fungi. The co-infection with several bacterial species (including S. epidermidis, K. pneumonia, Entrococcus and Bacillus subtitles) was seen in four HCW's dominant hand.

The duration of using such mobile phones during work-times were 3.85 years (SD 2.76) and 4.75 years (SD 3.33) in those with infected dominant hands and those not, respectively $(\mathrm{p}=0.07)$. Such differences were not statistically significant $(\mathrm{p}=0.58)$.

\section{DISCUSSION}

This study shows that near $40 \%$ of HCW's dominant hands and $32 \%$ of their mobiles phones had bacterial contaminations mostly with S. Epidermidis. Contamination to nosocominal species (Staphylococcus aureus, Klebsiella pneumonia, Enterococcus spp) was seen in 9 and 8 out of 149 HCWs dominant hand and mobile phones, respectively. Physicians, medical students, nurses and nurse aids had the same frequency of bacterial contaminations regarding both dominant hand and mobile phones. The kind of isolated microorganism from dominant hands correlated with the isolated ones from mobile phones.
The susceptibility to commonly used antimicrobials was similar for mobile phones and dominant hand of the HCWs. However, we observed a relatively high resistance rate to some of the commonly used antimicrobials (25\% for amoxicillin) which is clinically important and indicates inappropriate use of antimicrobials in teaching hospitals in Iran. The high resistance rate to commonly used antimicrobials in Iran has been reported by other investigators ${ }^{[22,23]}$.

The present study investigated mobile phone bacterial contamination, and found that most of the organisms isolated were skin flora. However, $16.7 \%$ of samples were positive for pathogens known to be associated with nosocomial transmission, such as enterococci spp, $\mathrm{S}$. aureus and $K$. pneumonia. Vancomycin-Resistant Enterococci (VRE) and Methicillin-Resistant S. Aureus (MRSA) were not isolated.

The hospital environment plays a critical role in the transmission of organisms associated with nosocomial infections. Micro-organisms can be transferred from person to person or from inanimate objects (such as stethoscopes, bronchoscopes, pagers, ballpoint pens, patient hospital charts ,computer keyboards, mobile phones and fixed telephones) to hands and vice versa $^{[4,6,8,11,13-18]}$.

Other investigators reported that telephones, intercoms, dictaphones and bedpan flusher handles may be contaminated with potentially pathogenic bacteria $^{[2,8,18,24,25]}$. Schultz et al.$^{[7]}$ reported that $95 \%$ of cultures from computer keyboards were positive for skin flora, and $5 \%$ were positive for pathogens known to be associated with nosocomial pathogens. Also Jeske et al. ${ }^{[12]}$ reported bacterial contamination of anesthetists' hands by personal mobile phone (38/40 physicians, $4 / 40$ with human pathogen bacteria) use in the operating theatre.

The use of mobile phones by HCWs in intensive care unit, burn wards and operative rooms may have more serious hygiene consequences, because unlike fixed phones, mobile phones are often used in the operating room close to the patients. Intensive care unit patients and burned patients are more vulnerable to infectious diseases, so the risk of transmission of organisms associated with nosocomial infections will be increased in these patients ${ }^{[12,26,27]}$. More than half of the British population owns a mobile phone, and increasing technological applications have led to increased use of these devices to provide better communication between healthcare workers (HCWs) and patients ${ }^{[5]}$. Innovations in mobile communication have led to better patient control of diseases; however the increased use of mobile phones is seen against a background rise in nosocomial infection rates ${ }^{[14-16]}$. 
Since the restriction of mobile phones use by HCWs is not practically an effective method for prevention of nosocomial infections spread, the development of effective preventive strategies for wellpracticed infection control plan is an essential need to encompass environmental decontamination, hand hygiene, surveillance, and contact isolation for prevention of such nosocomial infections ${ }^{[3,9,10]}$. Simple cleaning of computers and telephones with $70 \%$ isopropyl alcohol may decrease the bacterial load ${ }^{[10,28]}$.

Control measures are quite simple and can include engineering modifications, such as the use of hand free mobile phones cleaning and disinfection of appropriate mobile surfaces, and hand washing with or without gloving of pertinent personnel ${ }^{[25,28-31]}$. In general, the medical facility's resident infection control staff can advise as to that facility's routine control practices for medical devices. Observance of these simple control procedures can potentially decrease morbidity and mortality for patients and reduce medical care costs for hospitals and care giving organizations ${ }^{[10]}$.

\section{CONCLUSION}

In summary the results of this study showed microbial contamination of HCWs' mobile phones, which some of the contaminated microorganisms (Such as $S$. aureus) were epidemiologically important nosocomial drug resistant pathogens. Also some bacterial isolates were resistant to commonly used antimicrobials such as amoxicillin, gentamicin and cephalothin. So the development of effective preventive strategies for well-practiced infection control plan is an essential need to encompass nosocomial infections.

\section{ACKNOWLEDGMENT}

This study was supported by a grant from Tabriz Zakaria Pharm Co, Tabriz, Iran. We also appreciate the excellent cooperation and support of Dr Abdolah Zadeh ,M, MD, marketing manager ,Tabriz Zakaria Pharm Co, Tabriz, Iran.

\section{REFERENCES}

1. Singh, V., V. Aggarwal, S. Bansal, S.P. Garg and N. Chowdhary, 1998. Telephone mouthpiece as a possible source of hospital infection. J. Assoc. Phys. India, 46: 372-373. http://cat.inist.fr/?a Modele $=$ afficheN\&cpsidt $=10537096$.

2. Kennedy, K.J., D.E. Dreimanis, W.D. Beckingham and F.J. Bowden, 2003. Staphylococcus aureus and stethoscopes. Med J. Aust., 178: 468. http://www.ncbi.nlm.nih.gov/pubmed/12720501.
3. Data, I., D.R. Statistical, D.U. Microbial and F. Risk, et al., 2002. National Nosocomial Infections Surveillance (NNIS) system report 2000, data summary from January 1992-April 2000, issued June 2000. Am. J. Infect. Control, 28: 429-448. DOI: 10.1067/mic.2000.110544.

4. Brady, R.R., S.F. Fraser, M.G. Dunlop, S.P. Brown and A.P. Gibb, 2007. Bacterial contamination of mobile communication devices in the operative environment. J. Hosp. Infect., 66: 397-398. DOI: 10.1016/j.jhin.2007.04.015.

5. Brady, R.R., A. Wasson, I. Stirling, C. McAllister and N.N. Damani, 2006. Is your phone bugged? The incidence of bacteria known to cause nosocomial infection on healthcare workers' mobile phones. J. Hosp. Infect., 62: 123-125. DOI: 10.1016/J.Jhin.2005.05.005.

6. Bures, S., J.T. Fishbain, C.F. Uyehara, J.M. Parker and B.W. Berg, 2000. Computer keyboards and faucet handles as reservoirs of nosocomial pathogens in the intensive care unit. Am. J. Infect. Control, 28: 465-471. DOI: 10.1067/mic.2000. 107267.

7. Schultz, M., J. Gill, S. Zubairi, R. Huber and F. Gordin, 2003. Bacterial contamination of computer keyboards in a teaching hospital. Infect. Control Hosp. Epidemiol., 24: 302-303. DOI: 10.1086/ 502200.

8. Singh, D., H. Kaur, W.G. Gardner and L.B. Treen, 2002. Bacterial contamination of hospital pagers. Infect. Control Hosp. Epidemiol., 23: 274-276. DOI: $10.1086 / 502048$.

9. Farr, B.M., C.D. Salgado, T.B. Karchmer and R.J. Sherertz, 2001. Can antibiotic-resistant nosocomial infections be controlled? Lancet. Infect. Dis., 1: 38-45. DOI: 10.1016/S14733099(01)00020-2.

10. Neely, A.N. and D.F. Sittig, 2002. Basic microbiologic and infection control information to reduce the potential transmission of pathogens to patients via computer hardware. J. Am. Med. Inform. Assoc., 9: 500-508. DOI: 10.1197/jamia.M1082.

11. Goldblatt, J.G., I. Krief, T. Klonsky, D. Haller, V. Milloul and D.M. Sixsmith et al., 2007. Use of cellular telephones and transmission of pathogens by medical staff in New York and Israel. Infect. Control Hosp. Epidemiol., 28: 500-503. DOI: 10.1086/513446.

12. Jeske, H.C., W. Tiefenthaler, M. Hohlrieder, G. Hinterberger and A. Benzer, 2007. Bacterial contamination of anaesthetists' hands by personal mobile phone and fixed phone use in the operating theatre. Anaesthesia, 62: 904-906. DOI: 10.1111/j.1365-2044.2007.05172.x. 
13. Marinella, M.A., 1998. The stethoscope and potential nosocomial infection. Infect. Control Hosp. Epidemiol., 19: 477-478. http://www.mja. com.au/public/issues/178_09_050503/letters_0505 03-3.html.

14. Ferrer-Roca, O., A. Cardenas, A. Diaz-Cardama and P. Pulido, 2004. Mobile phone text messaging in the management of diabetes. J. Telemed. Telecare, 10: 282-285. DOI: 10.1258/1357633042026341.

15. Neville, R., A. Greene, J. McLeod, A. Tracey and J. Surie, 2002. Mobile phone text messaging can help young people manage asthma. Br. Med. J., 325: 600. DOI: 10.1136/bmj.325.7364.600/a.

16. Soto, R.G., L.F. Chu, J.M. Goldman, I.J. Rampil and K.J. Ruskin, 2006. Communication in critical care environments: mobile telephones improve patient care. Anesth. Analg, 102: 535-541. DOI: 10.1213/01.ane.0000194506.79408.79.

17. Vilella, A., J.M. Bayas, M.T. Diaz, C. Guinovart, C. Diez and D. Simo et al., 2004. The role of mobile phones in improving vaccination rates in travelers. Prev. Med., 38: 503-509. DOI: 10.1016/j.ypmed.2003.12.005.

18. Rafferty, K.M. and S.J. Pancoast, 1984. Brief report: Bacteriological sampling of telephones and other hospital staff hand-contact objects. Infect. Control, 5: 533-535. http://www.ncbi.nlm.nih.gov/ pubmed/6568216.

19. Dortet, L., P. Legrand, C.J. Soussy and V. Cattoir, 2006. Bacterial identification, clinical significance and antimicrobial susceptibilities of Acinetobacter ursingii and Acinetobacter schindleri, two frequently misidentified opportunistic pathogens. J. Clin. Microbiol., 44: 4471-4478. DOI: 10.1128/JCM.01535-06.

20. Ginocchio, C.C., 2002. Role of NCCLS in antimicrobial susceptibility testing and monitoring. Am. J. Health Syst. Pharm., 59: S7-11. http://www.ajhp.org/cgi/reprint/59/suppl_3/S7.

21. Zapantis, A., M.K. Lacy, R.T. Horvat, D. Grauer, B.J. Barnes and B. O'Neal et al., 2005. Nationwide antibiogram analysis using NCCLS M39-A guidelines. J. Clin. Microbiol., 43: 2629-2634. DOI: 10.1128/JCM.43.6.2629-2634.2005.

22. Feizabadi, M.M., G. Etemadi, D. Yadegarinia, M. Rahmati, S. Shabanpoor and S. Bokaei, 2006. Antibiotic-resistance patterns and frequency of extended-spectrum beta-lactamase-producing isolates of Klebsiella pneumoniae in Tehran. Med. Sci. Monit., 12: BR362-BR365. http://www. medscimonit.com/fulltxt.php?ICID $=484684$.
23. Hadadi, A., M. Rasoulinejad, Z. Maleki, M. Yonesian, A. Shirani and Z. Kourorian, 2008. Antimicrobial resistance pattern of Gram-negative bacilli of nosocomial origin at 2 university hospitals in Iran. Diagn Microbiol. Infect. Dis., 60: 301-305. DOI: 10.1016/j.diagmicrobio. 2007.10.010

24. Ciragil, P., M. Gul and M. Aral, 2006. Bacterial contamination of computers and telephones in a university hospital in Turkey. J. Hosp. Infect., 62: 247-248. Doi: 10.1016/j.jhin.2005.08.008

25. Neely, A.N. and M.P. Maley, 2001. Dealing with contaminated computer keyboards and microbial survival. Am. J. Infect. Control, 29: 131-132. Doi: 10.1067/mic.2001.114664

26. Neely, A.N., M.P. Maley, G.D. Warden, 1999. Computer keyboards as reservoirs for Acinetobacter baumannii in a burn hospital. Clin. Infect. Dis.,29: 1358-1360. Doi: 10.1086/313463

27. Trick, W.E., S.K. Fridkin, J.R. Edwards, R.A. Hajjeh and R.P. Gaynes, 2002. Secular trend of hospital-acquired candidemia among intensive care unit patients in the United States during 19891999. Clin. Infect. Dis., 35: 627-630. DOI: $10.1086 / 342300$

28. Rutala, W.A., 1996. APIC guideline for selection and use of disinfectants. 1994, 1995 and 1996 APIC Guidelines Committee. Association for professionals in infection control and epidemiology. Inc. Am. J. Infect. Control, 24: 313-342. Doi: 10.1016/S01966553(96)90066-8.

29. Hannigan, P. and J.W. Shields, 1998. Handwashing and use of examination gloves. Lancet, 351: 571. DOI: 10.1016/S0140-6736(05)78558-5.

30. Maley, M.P., 2000. Compliance with hand washing. Infect. Control Hosp. Epidemiol., 21: 4. DOI: $10.1086 / 503208$.

31. Neely, A.N. and M.P. Maley, 1999. Another disinfectant for enterococci. Infect. Control Hosp. Epidemiol., 20: 388-389. Doi: 10.1086/503133. 